\title{
Modelling of Cooling and Recrystallization Kinetics during Self-Annealing of Aluminium Coils
}

\author{
Alexander Nam ${ }^{1, a^{*}}$, Vasiliy Yashin ${ }^{2}$, Evgenii Aryshenskii ${ }^{1}$, Alexander Zinoviev ${ }^{3}$ \\ and Rudolf Kawalla ${ }^{1}$
}

\author{
${ }^{1}$ Technische Universität Bergakademie Freiberg, Institute of Metal Forming, \\ Bernhard-v.-Cotta Str.4, 09599 Freiberg, Germany \\ ${ }^{2}$ ZAO Alcoa SMZ, st. Alma-Atinskaya, 29, 443051, Russia, Samara \\ ${ }^{3}$ National University of Science and Technology MISIS, Leninsky Ave 4, 119049, Moskva, Russia \\ aalexander.nam@imf.tu-freiberg.de
}

Keywords: coil cooling, aluminium, recrystallization, hot rolling

\begin{abstract}
Study proposes a coil temperature model for aluminium alloys. The mathematical model is based on the $3 \mathrm{D}$ finite element method, which is implemented in MATLAB ${ }^{\circledR}$ using objectoriented programming approach. Owing to the used approach, several cooling steps of the coil can be performed including the coil transport and cooling in the storage area after the hot rolling. Individual cooling phases feature specific boundary conditions and time segments. The coefficients for the boundary conditions of the specific cooling phase were determined using parameter identification strategy. Furthermore, the temperature distribution of coil is used for the calculation the static recrystallization and grain size during coil cooling. The temperature model was validated within sufficient accuracy for each cooling phase using experimental data of the coil cooling after the conventional hot rolling at the Arconic's plant in Samara, Russia.
\end{abstract}

\section{Introduction}

Ongoing further development of the aircraft, motor vehicles, and food containers calls for the new aluminum alloys design and the improvements of existing ones. To achieve the required combination of mechanical properties of aluminum sheets and strips, the texture and structure evolution shall be controlled during the entire thermomechanical rolling process.

There are numerous simulations and experimental studies [1-4] focusing on the investigation and modelling of the microstructure evolution during aluminum thermomechanical treatment. The structure evolution of most common series of aluminum alloy (5XXX and $3 \mathrm{XXX}$ series) in distinctive sheet manufacturing stages is well investigated $[2,5,6]$ except annealing into the coil. The main difficult is complicated thermal process, which occurs in the coil during its coiling and cooling. The accuracy of this thermal calculation is critical for calculation of structure evolution inside the coil. For example, the heat transfer within the coil cannot be assumed comparable as in a solid body due to the layer structure of the coil $[7,8]$. The heat transfer across these layers strongly depend on various operational factors such as: surface quality, tension force, lubrication etc. must be taken into account [9].

As result, the accurate coil thermal field calculation is essential for the solving of the selfannealing and annealing problem. The following key aspects shall be accounted for in such calculations, i.e. the temperature distribution and its behavior in time. Besides, they become even more significant as coil parameters, e.g. weight, and geometrical dimensions, increase. Control and adjustment of these processes will enable achieving the required combination of properties in the semi-finished product.

There has been some attempts to solve this task for steel coil $[10,11]$, for example, for precipitation calculation [12]. However, authors do not find any articles, which have a detail description of structure evolution in aluminum coil during its cooling in the air after hot rolling or annealing. Usually regarding self-annealing, attention is given to the fact, whether recrystallization 
is occurred or not [13] without detail investigation of temperature and structure distinction inside in different layers of coil.

The objective of this article is to provide insight in static recrystallization processes during selfannealing of the coil of an aluminum alloy 5182 by means of the development of the coil temperature model and its integration with one of the Avrami equation established approach, describing recrystallization processes behavior [5].

\section{Coil Model}

The coil temperature model is evolved by the finite element method in $3 \mathrm{D}$ using the symmetry across the strip width. The model is implemented in MATLAB ${ }^{\circledR}$ software using object-oriented programming approach. Owing to the used approach [8], several cooling steps of the coil can be performed including the coil transport and cooling in the storage area. Individual cooling phases feature specific boundary conditions and time segments.

The governing equation for the temperature evolution in the coil and in the strip are given by the parabolic partial differential equation (PDE) of the heat diffusion, given by [14]:

$$
\frac{\partial}{\partial x}\left[k_{x} \frac{\partial T}{\partial x}\right]+\frac{\partial}{\partial y}\left[k_{y} \frac{\partial T}{\partial y}\right]+\frac{\partial}{\partial z}\left[k_{z} \frac{\partial T}{\partial z}\right]=\rho(T) C_{p}(T) \frac{\partial T}{\partial t}
$$

where $\mathrm{T}$ is the temperature of the coil and strip, $\mathrm{t}$ is the cooling time during process step, $k_{x, y, z}$ is the spatial-dependent thermal conductivity in the coil and strip, $\rho(T)$ is the temperature-dependent density, $c_{p}(T)$ is the temperature-dependent specific heat capacity.

The calculated temperature evolution in each process step is related to the time in the unsteady heat conduction problem. Therefore, the solution requires an initial condition. The initial condition, i.e. the initial temperature distribution, is the solution of the previous process step [15].

$$
T\left(x, y, z, t_{0 n}=0\right)=T_{0 n}
$$

where $t_{0 n}$ is the initial time of an appropriate processing step, $T_{0 n}$ is the initial temperature distribution in the coil or in the strip.

The boundary conditions comprise the combination of convective and radiation boundary conditions, which are taken into account the cooling of the coil in the environment due to convection and radiation. This boundary condition can be formulated as [15]:

$$
\begin{aligned}
& k(T) \frac{\partial T}{\partial n}=h_{c o n v}\left(T_{s}-T_{\infty}\right)+\sigma_{r a d} \varepsilon\left(T_{s}{ }^{4}-T_{\infty}{ }^{4}\right)=\left[h_{c o n v}+\sigma_{r a d} \varepsilon\left(T_{s}{ }^{2}+\right.\right. \\
& \left.\left.T_{\infty}{ }^{2}\right)\left(T_{s}+T_{\infty}\right)\right]\left(T_{s}-T_{\infty}\right)=h_{c t}\left(T_{s}-T_{\infty}\right)
\end{aligned}
$$

where $h_{\text {conv }}\left(T_{s}-T_{\infty}\right)$ is the thermal convection to the environment based on the Newton's law of cooling, $\sigma_{\text {rad }} \varepsilon\left(T_{s}{ }^{4}-T_{\infty}{ }^{4}\right)$ is the thermal radiation to the environment based on the StefanBoltzmann's law, $T_{S}$ is the surface temperature, $T_{\infty}$ is the environment temperature, $h_{\text {conv }}$ is the convective heat transfer coefficient of material to environment, $\sigma_{\text {rad }}$ is the coefficient of StefanBoltzmann, $\varepsilon$ is emissivity of surface, $h_{c t}$ is the heat transfer coefficient including convection and radiation impact.

\section{Parameter Identification of Boundary Conditions}

The unknown coefficients of boundary conditions (thermal convection to the environment and equivalent thermal conductivity through coil strip layers) were identified by parameter identification strategy [16] based on the experimental measurements of the coil after the conventional hot rolling with a final strip thickness of $0.0034 \mathrm{~m}$ at the Arconic's plant in Samara, Russia. The temperature measurements were performed by the pyrometers lengthwise along the strip width and in between first and last layer. The total number of layers was 188. The measurements occurred during the coil carry to the storage as well as its cooling in the warehouse. The result of these measurements and their positions are shown in Fig. 1. 

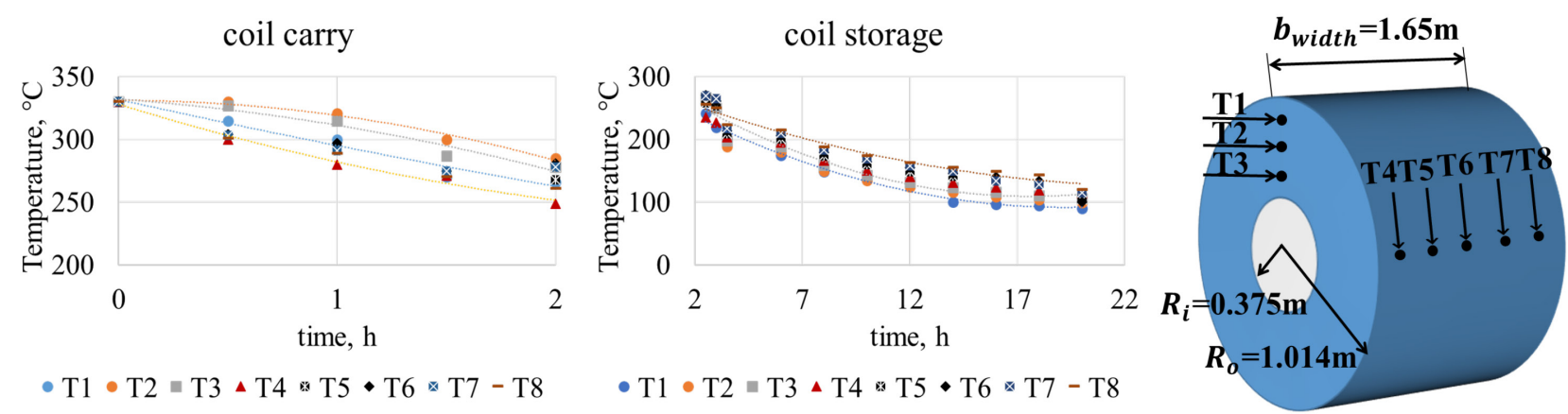

Fig. 1. Results of temperature measurements during coil carry and storage and measured positions (T1-T3 measured at $0.16 \mathrm{~m}$ interval; T4-T8 measured at $0.275 \mathrm{~m}$ interval)

The minimization of the goal function was performed using MATLAB Optimization Toolbox. The goal function is adapted to the following form

$$
\Phi(x)=\sqrt{\sum_{i=1}^{M} \sum_{j=1}^{N}\left(T_{i j}^{c}-T_{i j}^{m}\right)^{2}}
$$

where $T^{c}, T^{m}$ are the calculated and measured temperatures, corresponding, $\mathrm{M}$ is the number of measurements per time, and $\mathrm{N}$ is the number of measuring points.

\section{Static Recrystallization during Cooling}

Aluminum alloy 5182 is well investigated and some reliable model of its structure evolution have been already proposed $[5,13]$. The approach, which was developed in [5] is chosen. This semi empirical approach is suitable for the industrial calculations due to less computation efforts. Static recrystallization can be described by the usual Avrami equation:

$$
\begin{aligned}
& X_{S R X}=1-\exp \left(-0.693\left(\frac{t}{t_{0.5}}\right)^{n}\right) \\
& t_{0.5}=8.34 \times 10^{-7} d_{0}^{1.35} Z^{-0.73} \varepsilon^{-0.93} \exp \left(\frac{200000}{R T}\right)
\end{aligned}
$$

where $\mathrm{n}$ is Avrami constant, $\mathrm{t}_{0.5}$ - time for $50 \%$ recrystallization, $\varepsilon$ is pass strain, $d_{0}$ is initial grain size.

The mean grain size $\mathrm{d}_{\mathrm{SRX}}$ can be calculated

$$
d_{S R X}=12.690 Z^{-0.17} \varepsilon^{-0,37}
$$

where $\mathrm{Z}$ and $\varepsilon$ are Zener Hollomon parameter and total strain corresponding.

\section{Results}

Fig. 2 shows the temperature distribution within the coil and the comparison of measured and calculated temperatures during its carry and storage using determined coefficients. The results of the coil temperature during carry are located within $\pm 5 \%$ confidence interval, whereas temperature evolution during its storage is calculated with a accuracy of $\pm 10 \%$ depending of the temperature range. 


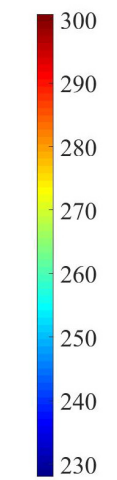

a)

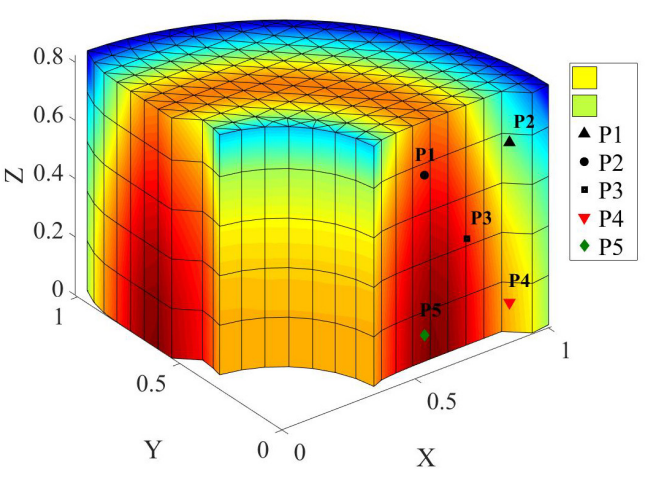

$\mathrm{X}$

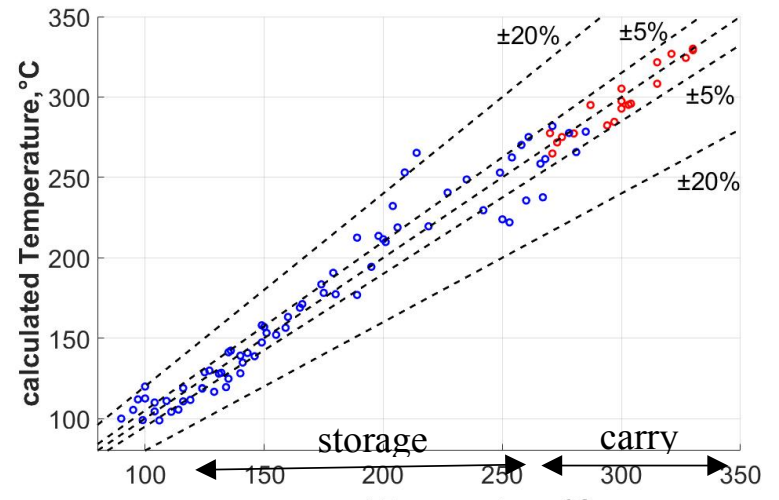

b)

Fig. 2. a) Temperature distribution within coil at the end of the coil carry; b) comparison between calculated and measured temperatures of coil cooling during its carry (o) and storage (o)

Subsequently, the investigation of the structure evolution during coil cooling was performed into 5 points within half coil cross-section (see Fig. 2a) according to Eq. 5-7. As result, the calculated temperature of the coil cooling in the air depicts slight gradient within the coil cross section and the static recrystallization occurs quite fast that is the typical picture for an aluminium alloy 5182 . The performed rolling conditions of the finishing train, consisting of five finishing rolling mills (F1-F5), and calculated static recrystallization during the hot rolling for the investigated coil are shown in Table 1.

Table 1. Schedule of performed finishing rolling trial

\begin{tabular}{|c|c|c|c|c|c|}
\hline & $\mathrm{F} 1$ & $\mathrm{~F} 2$ & $\mathrm{~F} 3$ & $\mathrm{~F} 4$ & $\mathrm{~F} 5$ \\
\hline${\text { Thickness } \mathrm{h}_{0}, \mathrm{~mm}}$ & 35 & 19.33 & 11.61 & 7.69 & 4.53 \\
\hline Thickness $\mathrm{h}_{1}, \mathrm{~mm}$ & 19.33 & 11.61 & 7.69 & 4.53 & 2.4 \\
\hline Rolling speed, $\mathrm{m} / \mathrm{min}$ & 26 & 47 & 77 & 138 & 244 \\
\hline Strain rate, $\mathrm{s}^{-1}$ & 2.57 & 6 & 11.8 & 28.2 & 68 \\
\hline Inlet temperature, ${ }^{\circ} \mathrm{C}$ & 440 & 396 & 379 & 337 & 359 \\
\hline Activation energy $\left(\mathrm{Q}_{\text {def }}\right.$ ) & \multicolumn{5}{|c|}{200000} \\
\hline Zener Hollomon parameter & $2.2 \mathrm{E}+14$ & $4.2 \mathrm{E}+15$ & $2 \mathrm{E}+16$ & $7.4 \mathrm{E}+16$ & $3.5 \mathrm{E}+17$ \\
\hline Inter pass time, s & 13.8 & 7.7 & 4.7 & 2.6 & $1.6^{*}$ \\
\hline $\begin{array}{c}\text { Static softening ratio during } \\
\text { inter pass time }\end{array}$ & 0.34 & 0.51 & 0.58 & 0.45 & 0.52 \\
\hline $\begin{array}{c}\text { Accumulated strain } \\
\text { (incl. static softening ratio) }\end{array}$ & 0.36 & 0.43 & 0.38 & 0.5 & 0.54 \\
\hline
\end{tabular}

*time between leaving last rolling mill and strip winding.

The mean grain size after last rolling pass was determined in [17] as $40 \mu \mathrm{m}$ which is used as an initial grain size. Furthermore, the calculation of the static recrystallization in coil revealed that the microstructure is fully static recrystallized after $10 \mathrm{~s}$ cooling, and it occurs uniformly within the coil (see Fig. 3a). Fig. 3b depicts the distribution of the static recrystallized grain size after $10 \mathrm{~s}$ cooling. The fully recrystallized average grain size was calculated about $13 \mu \mathrm{m}$. The predicted size is consistent with an experimentally measured one (see Fig.4). The measurements of the grain size were carried out according to the standard intersection method after ASTM E112-12. The distinction between head and tail was determined as $12 \mu \mathrm{m}$ and $11 \mu \mathrm{m}$, respectively. The evolution of the recrystallize fraction is also close to the experimentally and numerically defined in $[5,16]$. 

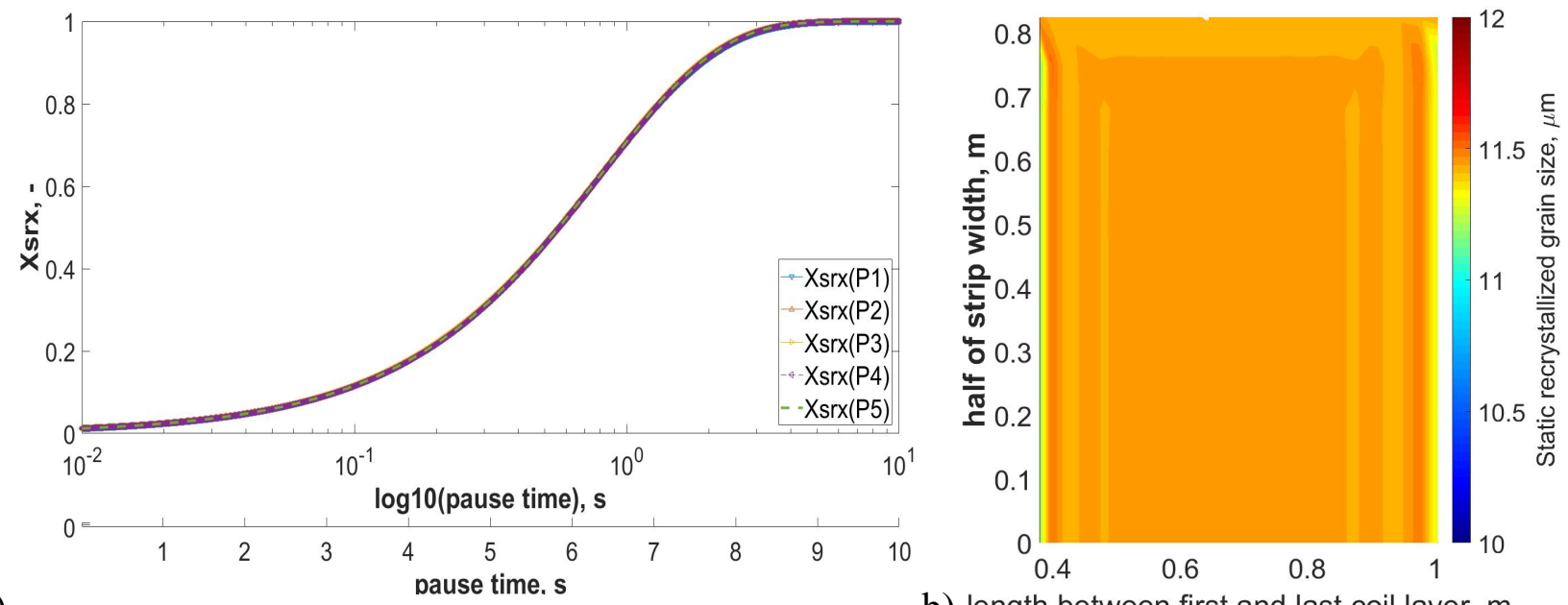

a)

b) length between first and last coil layer, $m$

Fig. 3. a) Static recrystallization within coil according to Avrami curve during coil cooling on the stage carry; b) grain size distribution in the cross section of the coil after $10 \mathrm{~s}$ cooling
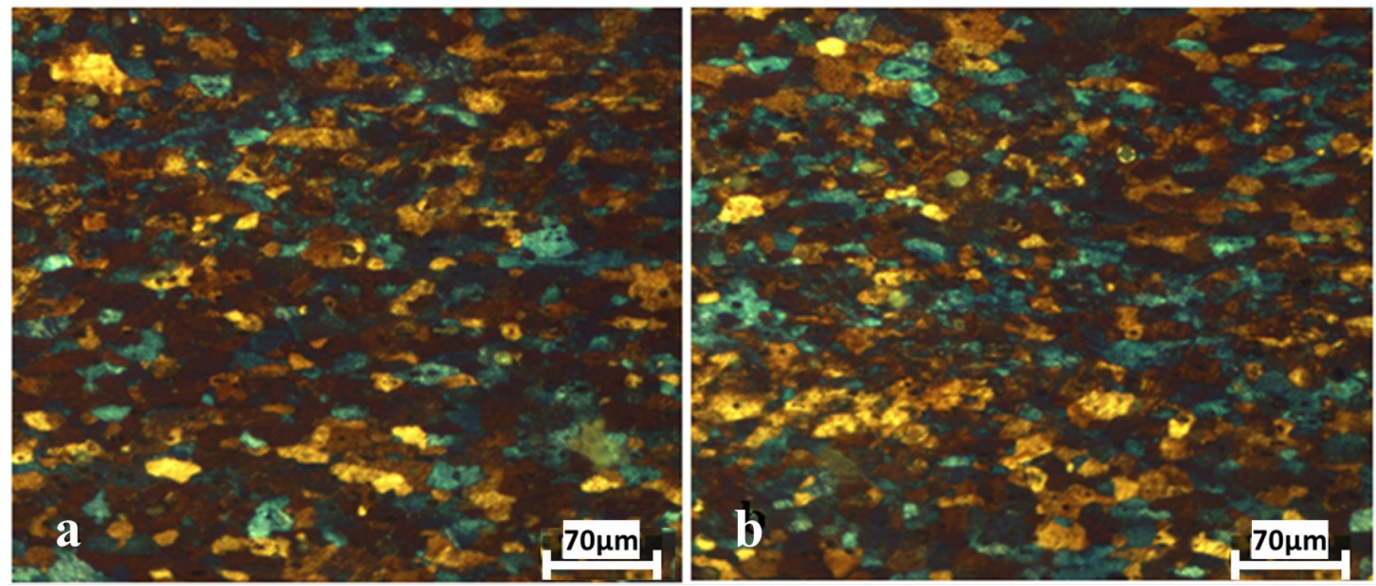

Fig. 4. Microstructure examination after self-annealing a) tail b) head of the coil taken from the middle of the strip

The wide variation range of the grain distribution inside a coil is not observer. It is caused by the fast recrystallization rate. The recrystallization is finished before occurring of temperature different inside a coil. However, the recrystallization of other alloys like AA5182 is characterized by a slower recrystallization rate. For example, for same rolling conditions, AA3104 will be completely recrystallized during $3 \mathrm{~min}$ [18], AA1050 during $166 \mathrm{~min}$ [19]. The scandium micro alloying inhibits seriously recrystallization or even completely prevent [20]. Hence, the time of the coil temperature above the recrystallization threshold can be not enough for full static recrystallization.

\section{Summary}

The experimental and numerical research enabled the design of the reliable model for the aluminium coil cooling. The calculation of the static recrystallization of AA5182 in coil revealed that the microstructure is fully static recrystallized after $10 \mathrm{~s}$ cooling, and it occurs uniformly within the coil. Although the coil possessed the temperature above recrystallization threshold during 2-3 hours based on experimental data. The recrystallization temperature threshold and coil cooling depend strongly on various parameters such as aluminium alloy (e.g. AA1050), coil geometry, rolling conditions etc. As a result, using such proposed strategy the self-annealing of aluminium coil can be investigated. 


\section{References}

[1] E. Aryshenskii, R. Kawalla, J. Hirsch, Development of New Fast Algorithms for Calculation of Texture Evolution during Hot Continuous Rolling of Al-Fe Alloys, steel research int. (2017) 1700053-n/a.

[2] J. Hirsch, Through Process Modelling, Materials Science Forum 519-521 (2006) 15-24.

[3] S.V. Rushchits, E.V. Aryshenskii, R. Kawalla, V. Serebryany, Investigation of Texture Structure and Mechanical Properties Evolution during Hot Deformation of 1565 Aluminum Alloy, Materials Science Forum 854 (2016) 73-78.

[4] J. Hjelen, R. Ørsund, E. Nes, On the origin of recrystallization textures in aluminium, Acta Metallurgica et Materialia 39 (1991) 1377-1404.

[5] M.A. Wells, I.V. Samarasekera, J.K. Brimacombe, E.B. Hawbolt, D.J. Lloyd, Modeling the microstructural changes during hot tandem rolling of AA5XXX aluminum alloys: Part III. Overall model development and validation, Metallurgical and Materials Transactions B 29 (1998) 709-719.

[6] J. Hirsch, Texture Evolution and Earing in Aluminium Can Sheet, Materials Science Forum 495-497 (2005) 1565-1572.

[7] S.-J. Park, B.-H. Hong, S.C. Baik, K.H. Oh, Finite Element Analysis of Hot Rolled Coil Cooling, ISIJ International 38 (1998) 1262-1269.

[8] A. Nam, U. Prüfert, M. Eiermann, R. Kawalla, Numerical Modeling of Thermal Evolution in Hot Strip Rolling of Magnesium Alloy, Key Engineering Materials 651-653 (2015) 207-212.

[9] K. Karhausen, W. Schneider, Effect of Material Property Changes on the Performance of Al Rolling Mills, Materials Science Forum 638-642 (2010) 247-254.

[10] Michael J. Ryan, Stephen G. R. Brown, Peter J. Eva, The Effect of Hot Mill Processing Temperature Variations on Final Coil Properties of Hot Rolled Steels, PR-362-179 - 2012 AISTech Conference Proceedings (2012) 1591-1600.

[11] S.S. Sahay, B.V. Harish Kumar, S.J. Krishnan, Microstructure evolution during batch annealing, Journal of Materials Engineering and Performance 12 (2003) 701-707.

[12] Z.D. Liu, D.Q. Jin, Samarasekera IV, J.K. Brimacombe, The application of microstructure engineering in steel coil cooling process, J. of Iron and Steel Research Intl 12 (2005).

[13] J. Hirsch, K. Karhausen, R. Kopp, Microstructure Simulation During Hot Rolling Of Al-Mg Alloys, ICAA4, Proceedings of the 4th International Conference on Al alloys, Atlanta/GA USA (1994) edited by T.H.Sanders, E.A.Starke, Georgia Inst. Tech. (1994).

[14] D.W. Hahn, M.N. Özișik, Heat conduction, third.ed., [elektronische Ressource], Wiley, Hoboken, NJ, 2012.

[15] M.N. Özişik, Heat conduction, third. ed., Wiley, New York, 2012.

[16] M. Pietrzyk, L. Madej, L. Rauch, D. Szeliga, Computational Materials Engineering: Achieving High Accuracy and Efficiency in Metals Processing Simulations, Elsevier Science \& Technology Books, 2015.

[17] E.V. Aryshenskii, V.Y. Aryshenskii, A.F. Grechnikova, E.D. Beglov, Evolution of Texture and Microstructure in the Production of Sheets and Ribbons from Aluminum Alloy 5182 in Modern Rolling Facilities, Metal Science and Heat Treatment 56 (2014) 347-352. 
[18] V.Y. Aryshenskii, Development of a mechanism of the desirable anisotropy and mechanical properties formation during hot rolling of aluminum strip for deep drawing. habilitation thesis, Samara, 2002.

[19] S.P. Chen, Recovery and Recrystallization Kinetics in AA1050 and AA3003 Aluminium Alloys (2003).

[20] M.S. Kaiser, Fractional Recrystallization Behaviour of Al-Mg Alloy with Different Sc Addition Content (2014). 